\title{
Modeling of hot air drying of coconut residue
}

\author{
Pattawee Wutthigarn, Jeerayut Hongwiangjan, Jiraporn Sripinyowanich Jongyingcharoen* \\ Department of Agricultural Engineering, Faculty of Engineering, King Mongkut's Institute of Technology Ladkrabang, Bangkok, \\ Thailand
}

\begin{abstract}
In this study, the effect of drying temperature $\left(50-110^{\circ} \mathrm{C}\right)$ on hot air drying characteristics of coconut residue was investigated. The drying time and drying rate (DR) were in the ranges of 540-100 min and $0.0048-0.0182 \mathrm{~g}$ water $/ \mathrm{g}$ dry matter $\cdot \mathrm{min}$ at the drying temperature of $50-110^{\circ} \mathrm{C}$, respectively. Six drying models (Lewis, Page, Henderson and Pabis, Logarithmic, Midilli et al, and linear-plus-exponential model) were used to determine the change in moisture ratio (MR) with drying time. The linear-plus-exponential model provided best fitting of the predicted MR to the experimental MR with the highest average $R^{2}$ of 0.9985 and the lowest $R M S E$ of 0.01463 . The variation of drying temperature with the constants and coefficient of the model was polynomial type. The generalized linear-plus-exponential model as a function of drying temperature gave best result of prediction of MR with the $R^{2}$ of 0.9709 .
\end{abstract}

\section{Introduction}

Coconut residue is the by-product of coconut milk extraction. It is high in fiber as almost double as the amount found in wheat bran [1]. To date, use of ground coconut residue as a wheat alternative is of interest. In addition to be renowned as high in fiber, coconut residue also considered as a good source of protein with gluten free. Ramaswamy [1] reported that flour from coconut residue can improve digestion, help regulate blood sugar, protect against diabetes, help prevent heart disease and cancer, and aid in weight loss.

Due to the extremely high amount of coconut residue leaving from the coconut milk extraction process of about 40 tons/day and the low drying capacity of the industries, a lot of coconut residue are spoiled each day. To solve the above problem, study on drying of coconut residue should be useful.

In the literature, several drying models are available for many fruits and vegetables. The models can be used to calculate the change in MR with time. It provides important parameters of drying optimization and is good for selection of the ideal drying conditions [2]. This study therefore focused on determining the best drying models for hot air drying of coconut residue.

As drying temperature is considered as the most important parameter of hot air drying, defining the constants or coefficients of the best models as a function of drying temperature is also important. Therefore, the aims of this study were to investigate the effect of drying temperature on drying characteristics of coconut residue undergoing hot air drying and to create the generalized drying model of coconut residue as a function of drying temperature.

\section{Materials and methods \\ 2.1 Material}

Coconut residue with the initial moisture content of 1.84 $\mathrm{g}$ water/g dry matter $\cdot \min$ was supplied by the Perfect Companion Group Co., Ltd., Samut Prakarn province, Thailand. The coconut residue (5 $\mathrm{kg}$ each) was packed in polyethylene bags and kept in a refrigerator at $4-5^{\circ} \mathrm{C}$. It was allowed to equilibrate at room temperature before using in all experiments.

\subsection{Experimental procedure}

Coconut residue was weighed $200 \mathrm{~g}$ and placed as single layer with the thickness of $1 \mathrm{~cm}$ on a drying tray. The experiment was carried out using a hot air oven (UF260, Memmert $\mathrm{GmbH}+\mathrm{Co} . \mathrm{KG}$, Schwabach, Germany) at the temperatures of $50,70,90$, and $110^{\circ} \mathrm{C}$. Air velocity was $1 \mathrm{~m} / \mathrm{s}$ for all treatments. The final moisture content required for the dried product was $0.03 \mathrm{~g}$ water/g dry matter. During drying, the coconut residue was weighed at the predetermined intervals for moisture content determination. Drying experiment at each drying temperature was triplicated and mean with standard deviation was reported herein.

\subsection{Drying characteristic determination}

Moisture content was determined in a hot air oven at $105^{\circ} \mathrm{C}$ for $24 \mathrm{~h}$ [3] and calculated using the following equation:

$$
M=\frac{W_{w}-W_{d}}{W_{d}}
$$

where $M, W_{w}$, and $W_{d}$ are moisture content (g water/g dry matter), wet weight of the material $(\mathrm{g})$, and dry weight of the material $(\mathrm{g})$, respectively.

Corresponding author: jiraporn.jo@kmitl.ac.th 
Followings are the questions for calculation of MR and DR:

$$
\begin{gathered}
M R=\frac{M_{t}-M_{e}}{M_{i}-M_{e}} \\
D R=\frac{M_{t+d t}-M_{t}}{d t}
\end{gathered}
$$

where $M_{i}, M_{t}, M_{e}$, and $\mathrm{M}_{t+\mathrm{d} t}$ are moisture content $(\mathrm{g}$ water/g dry matter) at initial, specific time, equilibrium, and $t+\mathrm{d} t$, respectively; and $t$ is drying time ( $\min )$.

\subsection{Mathematical modeling of drying curves}

Five semi-theoretical and empirical drying models (Table 1) were used for fitting with the drying curves of hot air drying of coconut residue. The nonlinear regression analysis for curve fitting was performed and goodness of fit between the models and the experimental data was evaluated using two criteria, including coefficient of determination $\left(R^{2}\right)$ and root mean square error (RMSE) as shown in eqs. (4) and (5).

$$
\begin{gathered}
R^{2}=1-\frac{\sum_{i=1}^{N}\left(M R_{\text {exp }, i}-M R_{\text {pre }, i}\right)^{2}}{\sum_{i=1}^{N}\left(M R_{\text {exp }, i}-\overline{M R}\right)^{2}} \\
R M S E=\left[\frac{1}{N} \sum_{i=1}^{N}\left(M R_{\text {pre }, i}-M R_{\text {exp }, i}\right)^{2}\right]^{1 / 2}
\end{gathered}
$$

where $M R_{\text {exp }, i}$ and $M R_{p r e, i}$ are the ith experimental and predicted MR, respectively; and $N$ is the number of

\begin{tabular}{|c|c|c|}
\hline $\begin{array}{c}\text { Model } \\
\text { No. }\end{array}$ & Model name & Model \\
\hline 1 & Lewis & $M R=\exp (-k t)$ \\
\hline 2 & Page & $M R=\exp \left(-k t^{n}\right)$ \\
\hline 3 & $\begin{array}{l}\text { Henderson and } \\
\text { Pabis }\end{array}$ & $M R=a \exp (-k t)$ \\
\hline 4 & Logarithmic & $M R=a \exp (-k t)+c$ \\
\hline 5 & Midilli et al. & $M R=\operatorname{aexp}\left(-k t^{n}\right)+b t$ \\
\hline 6 & $\begin{array}{l}\text { Linear-plus- } \\
\text { exponential }\end{array}$ & $M R=\exp \left(-k t^{n}\right)+b t+c$ \\
\hline
\end{tabular}
observations.

Table 1 Mathematical drying models applied for hot air drying of coconut residue [4].

To create the generalized drying model, the relationship between constants and coefficients (coc) in the best drying model with drying temperature $(T)$ was determined by multiple regression analysis using the following equations:

$\begin{array}{ll}\text { Linear type } & \operatorname{coc}=a+b T \\ \text { Power type } & \operatorname{coc}=a T^{b} \\ \text { Exponential type } & \operatorname{coc}=a \exp (b T) \\ \text { Arrhenius type } & c o c=a \exp \left(\frac{-b}{8.314 T}\right) \\ \text { Logarithmic type } & \operatorname{coc}=a+b \ln (T) \\ \text { Polynomial type } & \operatorname{coc}=a+b T+c T^{2}\end{array}$

The equation with the greatest $R^{2}$ was selected as the best equation for describing the relationship of $c o c$ and $T$.
The performance of the generalized model was also evaluated using $R^{2}$. Drying curves showing comparison between experimental MR and predicted MR calculated from the generalized model were presented as well.

\section{Results and discussion}

\subsection{Drying characteristics}

DR curves of hot air drying of coconut residue are illustrated in Figs. 1 and 2. DR of every treatments started to decrease since the first 5 min of drying. The suitable drying times to reach the final moisture content of dried coconut residue ( $0.03 \mathrm{~g}$ water/g dry matter) were $540,240,150$, and $100 \mathrm{~min}$ at the drying temperatures of $50,70,90$, and $110^{\circ} \mathrm{C}$, respectively. Although no constant rate period was observed in these experiments, DR during the falling rate period gradually decreased with MR. The average DR at the drying temperatures of $50,70,90$, and $110^{\circ} \mathrm{C}$ were $0.0048,0.0088,0.0136$, and $0.0182 \mathrm{~g}$ water/g dry matter $\cdot \mathrm{min}$, respectively. It is clear from the above results that drying temperature had a considerable effect on drying time and DR of coconut residue. The drying time decreased substantially with increasing drying temperature. The values of DR almost doubled when the drying temperature was increased by $20^{\circ} \mathrm{C}$.

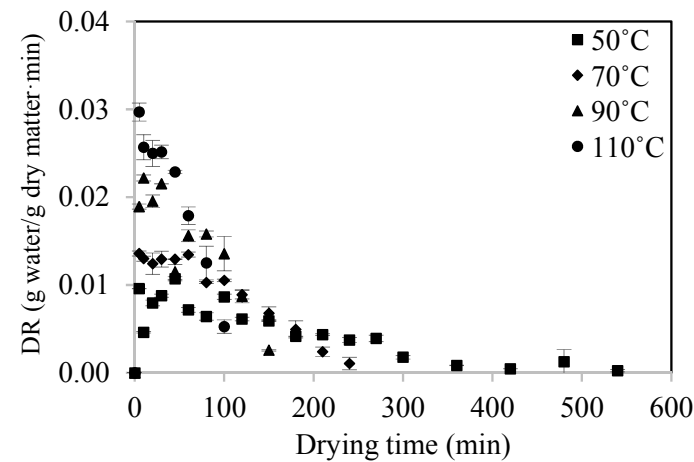

Fig. 1 DR versus drying time of hot air drying of coconut residue at different drying temperatures.

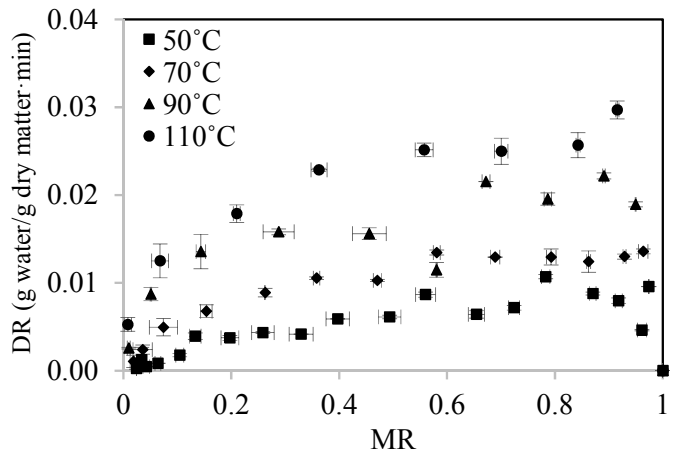

Fig. 2 DR versus MR of hot air drying of coconut residue at different drying temperatures. 
Table 2 Constants and coefficients and statistical analysis for the drying models of coconut residue.

\begin{tabular}{|c|c|c|c|c|c|c|c|c|}
\hline Model No. & $\mathrm{T}\left({ }^{\circ} \mathrm{C}\right)$ & $\mathrm{k}$ & $\mathrm{n}$ & $\mathrm{c}$ & $\mathrm{a}$ & $\mathrm{b}$ & $\mathrm{R}^{2}$ & RMSE \\
\hline \multirow[t]{5}{*}{1} & 50 & 0.0062 & & & & & 0.9928 & 0.03063 \\
\hline & 70 & 0.0060 & & & & & 0.9927 & 0.02393 \\
\hline & 90 & 0.0153 & & & & & 0.9696 & 0.06356 \\
\hline & 110 & 0.0233 & & & & & 0.9737 & 0.06044 \\
\hline & & & & & & ave. & 0.9822 & 0.04464 \\
\hline \multirow[t]{5}{*}{2} & 50 & 0.0024 & 1.186 & & & & 0.9993 & 0.01006 \\
\hline & 70 & 0.0028 & 1.156 & & & & 0.9994 & 0.00697 \\
\hline & 90 & 0.0035 & 1.356 & & & & 0.9912 & 0.03609 \\
\hline & 110 & 0.0060 & 1.364 & & & & 0.9960 & 0.02527 \\
\hline & & & & & & ave. & 0.9965 & 0.01960 \\
\hline \multirow[t]{5}{*}{3} & 50 & 0.0065 & & & 1.037 & & 0.9952 & 0.02578 \\
\hline & 70 & 0.0062 & & & 1.026 & & 0.9955 & 0.01959 \\
\hline & 90 & 0.0163 & & & 1.049 & & 0.9745 & 0.06140 \\
\hline & 110 & 0.0247 & & & 1.051 & & 0.9788 & 0.05808 \\
\hline & & & & & & ave. & 0.9860 & 0.04121 \\
\hline \multirow[t]{5}{*}{4} & 50 & 0.0058 & & -0.0537 & 1.080 & & 0.9970 & 0.02070 \\
\hline & 70 & 0.0043 & & -0.2654 & 1.276 & & 0.9991 & 0.00927 \\
\hline & 90 & 0.0087 & & -0.4159 & 1.427 & & 0.9953 & 0.02784 \\
\hline & 110 & 0.0143 & & -0.3435 & 1.359 & & 0.9974 & 0.02188 \\
\hline & & & & & & ave. & 0.9972 & 0.01992 \\
\hline \multirow[t]{5}{*}{5} & 50 & 0.0021 & 1.213 & & 0.992 & 0.000010 & 0.9993 & 0.01018 \\
\hline & 70 & 0.0031 & 1.121 & & 1.000 & -0.000146 & 0.9994 & 0.00774 \\
\hline & 90 & 0.0048 & 1.227 & & 0.986 & -0.000798 & 0.9962 & 0.02695 \\
\hline & 110 & 0.0073 & 1.269 & & 0.987 & -0.000823 & 0.9991 & 0.01394 \\
\hline & & & & & & ave. & 0.9985 & 0.01470 \\
\hline \multirow[t]{5}{*}{6} & 50 & 0.0021 & 1.212 & -0.0085 & & 0.000026 & 0.9993 & 0.01006 \\
\hline & 70 & 0.0031 & 1.121 & -0.0001 & & -0.000146 & 0.9994 & 0.00774 \\
\hline & 90 & 0.0048 & 1.228 & -0.0145 & & -0.000724 & 0.9962 & 0.02688 \\
\hline & 110 & 0.0072 & 1.268 & -0.0137 & & -0.000719 & 0.9991 & 0.01385 \\
\hline & & & & & & ave. & 0.9985 & 0.01463 \\
\hline
\end{tabular}

\subsection{Modeling of drying curves}

Drying curves presenting the changes in MR with time during hot air drying of coconut residue are shown in Fig. 3. As seen in these curves, MR decreased exponentially with drying time. In this study, 6 drying models with exponential terms were used to describe the drying curves. The constants and coefficients of these models for coconut residue undergoing hot air drying at the temperatures of $50,70,90$, and $110^{\circ} \mathrm{C}$ are presented in Table 2. The statistical criterion used for model selection, i.e. $R^{2}$ and $R M S E$, are also given in the Table with their average values in bold characters. The results show that average $R^{2}$ of four models (Page, Logarithmic, Midili et al., and linear-plus-exponential models) were higher than 0.99 . The findings are in accordance with the review of Onwude et al. [5], the Lewis, Midilli et al., Page, 2-term, logarithmic, Midified Page, and the approximation of diffusion models were the most suitable models in describing the drying behavior of fruits and vegetables. In this study, Model 6, the linearplus-exponential model, had the highest average $R^{2}$ of 0.9985 and the lowest RMSE of 0.01463 . Therefore, the linear-plus-exponent model was proposed to be the best model for describing the MR of coconut residue undergoing hot air drying for interval of drying temperature in this study. The linear-plus-exponential model was first introduced for modeling of drying curves by Sripinyowanich and Noomhorm [4]. They reported that this model can provide reasonable trend of moisture loss with time. The typical exponential model like the Page model ultimately decreases the MR value to zero while the linear-plus-exponential model adjusts well to the characteristic of moisture loss during the last falling rate period, the remaining moisture is strongly bound and cannot totally disappear at the end point of drying.

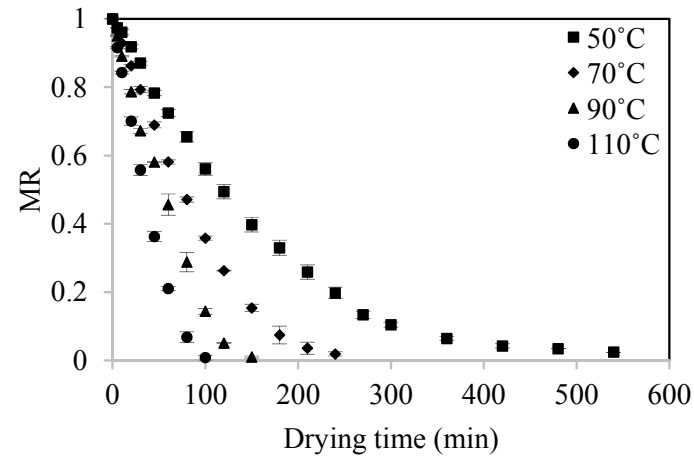

Fig. 3 Drying curves of hot air drying of coconut residue at different drying temperatures.

To combine the effect of drying temperature in the selected models, the constants and coefficients of the models were derived as a function of drying temperature. The polynomial type equation was the best in describing the relationship between the constants and coefficients of the models and the drying temperature. The generalized model with the regression equations of the constants and coefficients of the linear-plus-exponential model against drying temperature is expressed as:

Corresponding author: jiraporn.jo@kmitl.ac.th 


$$
M R(b, c, k, n, t)=\exp \left(-k t^{n}\right)+b t+c
$$

where

$$
\begin{gathered}
k=0.0030-6.4 \times 10^{-4} \mathrm{~T}+9.3 \times 10^{-7} T^{2} \\
n=1.58-0.0116 \mathrm{~T}+8.2 \times 10^{-5} T^{2} \\
c=-0.0257+6.2 \times 10^{-4} \mathrm{~T}-4.8 \times 10^{-6} T^{2} \\
b=0.0014-3.2 \times 10^{-5} \mathrm{~T}+1.1 \times 10^{-7} T^{2}
\end{gathered}
$$

This generalized linear-plus-exponential model can be used to estimate the MR of coconut residue subjected to hot air drying at any drying temperature and time in the interval of study with the average $R^{2}$ of 0.9709 . The drying curves of experimental and predicted MR using the generalized model are illustrated in Fig. 4. Residual plots were also examined to measure the model adequacy (Fig. 5). The residual patterns mostly depict overpredicted values. This means that the predicted MR values were mostly higher than the corresponding experimental MR values. Fig. 6 also presents validation of the generalized model using plots of the experimental MR versus the predicted MR. It is observed that the experimental MR versus the predicted MR were in consistency as the data points approximately banded around the reference $1: 1$ line, especially for the $50^{\circ} \mathrm{C}$ and $110^{\circ} \mathrm{C}$ treatments.

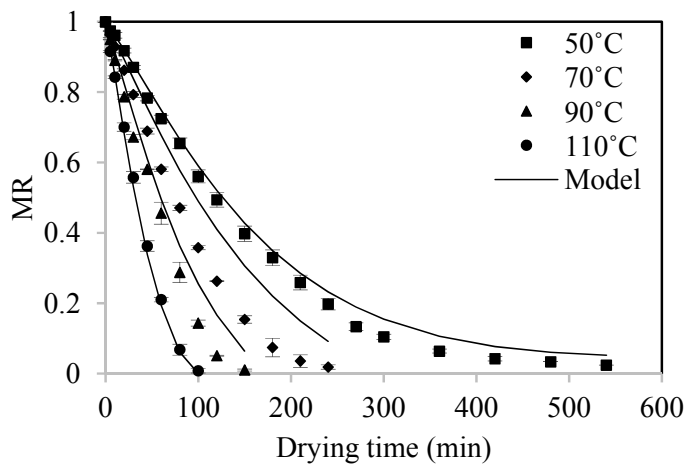

Fig. 4 Experimental and predicted drying curves of coconut residue at different drying temperatures by the generalized linear-plus-exponential model.

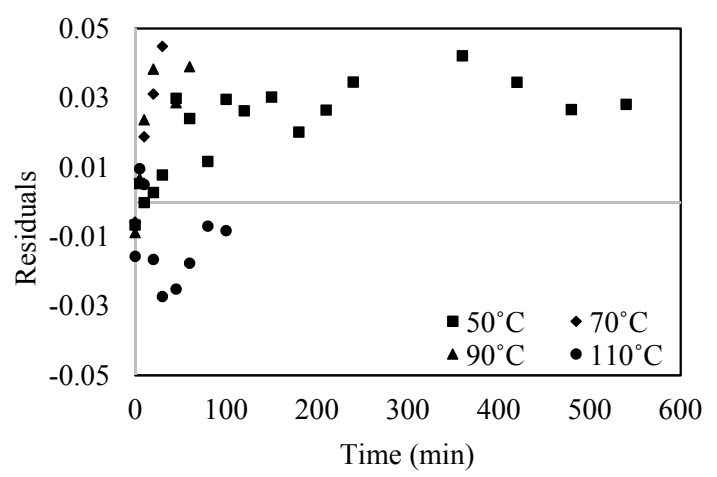

Fig. 5 Residual plot of the generalized linear-plus-exponential model for coconut residue undergoing hot air drying at different drying temperatures.

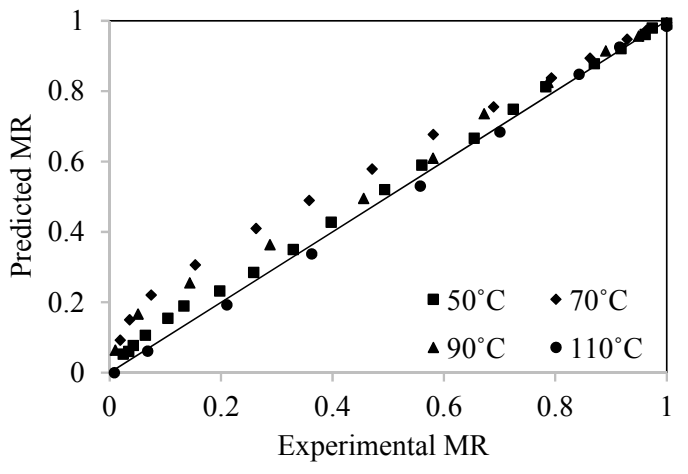

Fig. 6 Comparisons of experimental and predicted MR of coconut residue at different drying temperatures by the generalized linear-plus-exponential model.

\section{Conclusion}

Drying temperature had a considerable effect on drying characteristics of coconut residue subjected to hot air drying. Increasing drying temperature by $20^{\circ} \mathrm{C}$ resulted in shortening drying time by $50 \mathrm{~min}$ or higher and improving DR as almost double.

The hot air drying of coconut residue occurred in the falling rate period. Among the six drying model, the linear-plus-exponential model was the best in describing the change in MR of coconut residue with time in the temperature range of $50-110^{\circ} \mathrm{C}$.

The generalized linear-plus-exponential model taking into account the effect of drying temperature provided good fitting of the predicted MR to the experimental MR with the $R^{2}$ of 0.9709 . It would be useful engineering application for hot air drying of coconut residue.

\section{References}

1. L. Ramaswamy, International Journal of Ayurvedic and Herbal Medicine 4, 1426-1436 (2014)

2. P. Suvanvisan, E. Cheevitsopon, J.S. Jongyingcharoen, the $10^{\text {th }}$ TSAE International Conference, 36-41 (2017)

3. AOAC, Official methods of analysis (Association of Official Agricultural Chemists, Washington, DC., 1995)

4. J. Sripinyowanich, A. Noomhorm, Drying technology 29, 735-748 (2011)

5. D.I. Onwude, N. Hashim, R.B. Janius, N.M. Nawi, K. Abdan, Comprehensive Reviews in Food Science and Food Safety, doi: 10.1111/1541-4337.12196 (2016) 